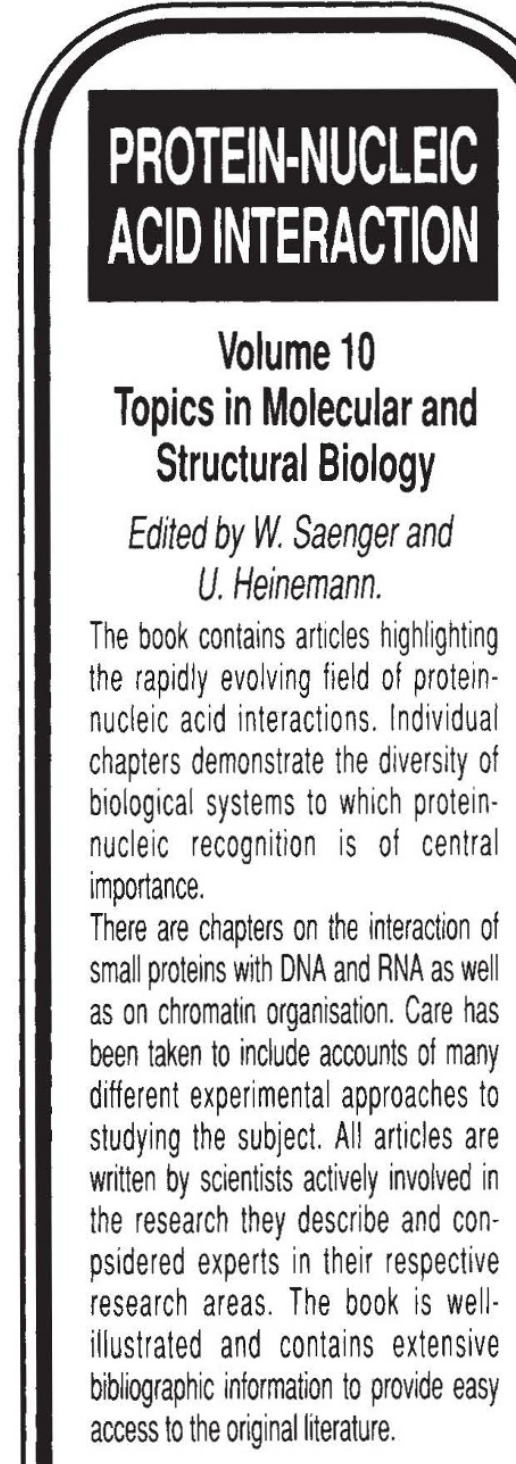

Contents DNA-Protein Interactions in the Regulation of Gene Expression - P.H. von Hippel (University of Oregon, Eugene, USA) and O.G. Berg (Uppsala University, Sweden). / Structures of Protein-Nucleic Acid Complexes in Solution by Electro-optical Analysis - D . Porschke and J. Antosiewicz (Max-Plank Inst. Gottingen. FRG). / NMR Studies of Protein-DNA Recognition. The Interaction of LAC Repressor Headpiece with Repressor DNA - R. Kaptein. R. Boelens and R.M.J.N. Lamerich (University of Utrecht. Holland). I The Single-stranded DNA Binding Protein of Escherichia coli - J. Greipel, C. Urbanke and G. Maass (Medizinische Hochschule. Hannover. FRG) I Protein Nucleic Acid Interaction in Tobacco Mosaic Virus - G Stubbs (Vanderbilt University. Nashville. USA). Structural and Functional Studies of Ribonuclease T1 U. Heinemann and U. Hahn (Freie Universitat. Berlin FRG). / Tet Repressor-Tet Operator interaction - W. Hillen and A. Wissmann (Inst.. Mikrobiol. and Biochem. Eriangen. FRG) / Structure and Condensation of Chromatin -M.H.J. Koch (DESY. Hamburg. FRG). Conclusion/Index

July $1989 £ 40.00214 p p 234 \times 156 \mathrm{~mm}$ $0-333-45321-2$

This book is available from your usual bookseller or from: Dionne Stocking, Macmillan Press Ltd, Houndmills, Basingstoke RG21 2XS, UK

\section{Grounds for agreement}

\section{John A. Endler}

Analytical Biogeography: An Integrated Approach to the Study of Animal and Plant Distributions. Edited by Alan A. Myers and Paul S. Giller. Chapman \& Hall: 1988. Pp. 578. £49.50, \$87.50.

BIOGEOgRAPHY is as basic to biology as evolution, but the subject's development has been hindered by three historical constraints. First, until the pioneering work of D. Rosen, MacArthur and Wilson, it had largely stagnated into data collection and narrative model-making. Second, the past 20 years have been so filled with dispute that it has been difficult for outsiders to take the subject seriously. And third, biogeography became so fragmented that schools representing different approaches ignored each others' work; it was essentially impossible, even in textbooks, to get an idea of the full range of the subject. Analytical Biogeography shows that things have changed, and that biogeography can be a fascinating, rigorous and unified subject.

The editors have done an admirable job of selecting subjects and authors. Only two topics have been missed - the use of statistical tests for non-random spatial patterns and specific biogeographical hypotheses (for example the Mantel test and spatial autocorrelation); and the use of unintentional and intentional introductions of organisms in experimental biogeography. Moreover, only a trace of the former animosity between different schools is evident. Although there are contradictions among the chapters, the authors have made a serious and usually successful effort to discuss both the strengths and weaknesses of their own approaches, and to refer to other chapters. In addition, the editors' introductions to each section put the individual contributions in a broad perspective.

The sections are arranged by biogeographical perspectives, patterns, processes and reconstruction. But the chapters more naturally fall into groups with common approaches in different timescales: current and fossil evidence, static and dynamic interpretations, and ecological and historical processes. Biogeography aims to explain the distribution of organisms on all time-scales, past and present. But some contributors (Brown, Williamson, Parsons, T. Schoener, A. Schoener) concentrate on smaller timescales (ecological), while others (Brundin, Humphries et al., Craw) concentrate on larger ones (evolutionary, geological or historical). The respective aims and methods vary; they have different implica- tions for the spatial scale of pattern and the processes which affect the maintenance, changes in and origins of geographical distributions. Studies of small timescale patterns and processes tend to concentrate on extant species, static (equilibrium) phenomena and ecological explanations, while those of large timescale patterns tend to emphasize timedependent processes, and geological. phylogenetic and evolutionary interpretations. Although small time-scale phenomena are potentially observable and subject to experimentation, they cannot directly address long-term phenomena; large time-scale studies can make use of both extant and fossil data (see especially B. Rosen's chapters), but can never be experimental. Both extremes have their strengths and weaknesses, so the most productive approaches use several time-scales and consider equally all possible processes (Myers and Giller. B. Rosen, Major, Marshall, Lynch).

One of the biggest problems is how to assess the relative importance of historical and ecological factors (Myers and Giller, B. Rosen, Lynch). This is not merely a matter of scale, because long time-scales allow time for convergent evolution, which can distort or obscure the effects of historical processes. For example, Craw discusses Croizat's proposal, based upon panbiogeography of vegetative morphology, of a novel close relationship between three carnivorous plant families. The analysis yields a transformation series linking the families' floral morphology, which is incongruent with vegetative morphology. But their vegetative morphology functions in trapping insects in habitats with low soil nutrients; the transformation series is distorted by convergent evolution driven by common ecological conditions. A converse example is that sympatric plant species often have divergent leaf morphology which may result from historical rather than ecological processes.

A key problem in the foregoing studies, and throughout biogeography, is the dearth of specific predictions for each of many possible hypotheses. In fact it was the few specific hypotheses which set the separate biogeographical schools on their way. Analytical Biogeography makes the gaps explicit and comprehensible for the first time.

John A. Endler is a Professor in the Department of Biological Sciences, University of California, Santa Barbara, California 93106, USA.

- Eugene P. Odum has written what he himself calls a hybrid volume - in part a revision of his textbook Ecology, in part "a citizen's guide" to the principles of the subject. Entitled Ecology and Our Endangered Life-Support Systems. the book is published by Sinauer Associates. Sunderland. Massachusetts, and distributed in Britain by W.H. Freeman. Price in pbk $\$ 14.95$. filo. 95 